\title{
The Relationship of Serum Calcium, Phosphorus, and Parathyroid Hormone with Renal Function in Elderly Osteoporotic Patients with No History of Chronic Kidney Disease
}

\author{
Hiroshi Yonezu*, Hiroshi Mikami, Koichi Oba, Katsutoshi Miyatake, \\ Michihiro Takai, Akihiro Nitta
}

Department of Orthopedics, Yoshinogawa Medical Center, Yoshinogawa, Japan

Email: ^hyonezu@kj9.so-net.ne.jp

How to cite this paper: Yonezu, H., Mikami, H., Oba, K., Miyatake, K., Takai, M. and Nitta, A. (2017) The Relationship of Serum Calcium, Phosphorus, and Parathyroid Hormone with Renal Function in Elderly Osteoporotic Patients with No History of Chronic Kidney Disease. Advances in Aging Research, 6, 55-60.

https://doi.org/10.4236/aar.2017.64006

Received: June 22, 2017

Accepted: July 16, 2017

Published: July 19, 2017

Copyright (c) 2017 by authors and Scientific Research Publishing Inc. This work is licensed under the Creative Commons Attribution International License (CC BY 4.0).

http://creativecommons.org/licenses/by/4.0/

(c) (i) Open Access

\begin{abstract}
The prevalence of osteoporosis and decline in renal function increases with age. Therefore, the coexistence rate of both these conditions rises in the elderly population. Abnormalities in mineral bone metabolism are major complications in chronic kidney disease (CKD). However, in elderly osteoporotic patients without a history of $\mathrm{CKD}$, there are few reports on the relationship between calcium (Ca), phosphorus $(\mathrm{P})$, and parathyroid hormone (PTH), and renal function. The purpose of this study was to investigate the relationship between $\mathrm{Ca}, \mathrm{P}$, and $\mathrm{PTH}$, and renal function in elderly osteoporosis patients with no history of CKD. We evaluated 169 patients who had been treated for osteoporosis. The eGFR decreased with age resulting in a negative correlation $(\mathrm{r}=-0.514, p<0.01)$. On the other hand, intact PTH increased with age resulting in an equilateral correlation $(\mathrm{r}=0.202, p<0.01)$. P increased, therefore $\mathrm{Ca}$ increased, resulting in an equalitarian correlation $(\mathrm{r}=0.309, p<0.01)$. In addition, an increase in intact PTH negatively correlated with a decrease in $\mathrm{Ca}$ and $\mathrm{P}(\mathrm{r}=-0.403, p<0.01$ and $\mathrm{r}=-0.416, p<0.01$, respectively). Even if $\mathrm{Ca}$ and $\mathrm{P}$ are in the normal range, in case of a poor effect of an osteoporotic therapeutic drug, it is necessary to consider the measurement of intact PTH in elderly osteoporosis patients with no history of CKD.
\end{abstract}

\section{Keywords}

Calcium, Phosphorus, Parathyroid Hormone, Renal Function, Elderly Osteoporotic Patients 


\section{Introduction}

The prevalence of osteoporosis and decline in renal function increases with age. Therefore, the coexistence rate of both these conditions rises in the elderly population. A decline in renal function influences bone metabolism, including secondary hyperparathyroidism, vitamin D deficiency, hypocalcemia, and high phosphorus (P). On the contrary, osteoporosis and osteoporotic therapeutic drugs can affect renal function by inducing injury to the blood vessels by $\mathrm{P}$ released from the bone. Furthermore, renal function can decline with the presence of hypercalcemia, calcium (Ca) preparation, and vitamin D preparation.

Abnormalities in mineral bone metabolism are major complications in chronic kidney disease (CKD). For example, it was reported that the risk of hip fracture was high in patients with moderate to severe CKD [1]. In the international guidelines set by KDIGO (Kidney Disease: Improving Global Outcome) [2], osteoporotic treatment is generally administered in CKD stages 1 - 2. At CKD stages $3-5$, it is recommended that $\mathrm{P}$ and $\mathrm{Ca}$ are managed, which mutually affect the parathyroid hormone (PTH) levels. However, in elderly osteoporotic patients without a history of $\mathrm{CKD}$, there are few reports on the relationship of $\mathrm{Ca}, \mathrm{P}$, and $\mathrm{PTH}$, with renal function.

The purpose of this study was to investigate the relationship between $\mathrm{Ca}, \mathrm{P}$, and $\mathrm{PTH}$, and renal function in elderly osteoporosis patients with no history of CKD.

\section{Materials and Methods}

We evaluated 169 patients who had been treated for osteoporosis at Yoshinogawa Medical Center, from April 2015 to July 2016 (15 men, 154 women; mean age 75.8 years old).We excluded cases previously treated for diabetes, internal secretion disease, and CKD. The drugs used were vitamins D 135 example, vitamins K 43 example, bisphosphonate 51 example, and selective estrogen receptor modulators (SERM) 10 example (there was overlap in use).Examination of the blood included measurement of $\mathrm{Ca}, \mathrm{P}$, bone-specific alkaline phosphatase (BAP; a marker of bone formation), tartrate-resistant acid phosphatase 5b (TRACP5b; a marker of bone resorption), intact $\mathrm{PTH}$, and estimated glomerular filtration rate (eGFR). Bone mineral density (BMD) was measured at the levels of the lumbar spine and proximal femur using dual-energy $\mathrm{X}$-ray absorptiometry.

Values are shown as mean \pm standard error (SE). Correlations between two independent measurements were assessed using the Pearson's correlation coefficient. Differences were considered statistically significant at $p$ values of $<0.05$. All statistical analyses were performed using SPSS version 21.0 (IBM).

\section{Results}

The results of the measurements are shown in Table 1. CKD stage 3 - 4 was observed in $29.6 \%$ of patients (Table 2 ). The eGFR decreased with age resulting in a negative correlation $(\mathrm{r}=-0.514, p<0.01)$. On the other hand, intact PTH increased with age resulting in an equilateral correlation $(\mathrm{r}=0.202, p<0.01)$. 
Table 1. Characteristics of studied cases.

\begin{tabular}{cccc}
\hline Parameter & Mean & Unit & Standard value \\
\hline eGFR & $68.2 \pm 18.4$ & $\mathrm{ml} / \mathrm{min} / 1.73 \mathrm{~m}^{2}$ & $\geq 90$ \\
Intact PTH & $40.1 \pm 21.1$ & $\mathrm{pg} / \mathrm{ml}$ & $10-65$ \\
Ca & $9.3 \pm 0.4$ & $\mathrm{mg} / \mathrm{dl}$ & $8.5-10.2$ \\
P & $3.4 \pm 0.5$ & $\mathrm{mg} / \mathrm{dl}$ & $2.5-4.5$ \\
BAP & $15.0 \pm 7.6$ & $\mathrm{U} / \mathrm{L}$ & $3.8-22.6$ \\
TRACP5b & $328.9 \pm 185.0$ & $\mathrm{mU} / \mathrm{dl}$ & $120-420$ \\
Lumbar BMD & $82.2 \pm 16.9$ & $\%(\mathrm{YAM})$ & \\
Proxymal Femoral BMD & $76.7 \pm 13.8$ & $\%(\mathrm{YAM})$ & \\
\hline
\end{tabular}

BAP: bone specific alkaline phosphatase; TRACP-5b: tartrate-resistant acid phosphatase 5b; YAM: Young Adult Mean.

Table 2. Chronic kidney disease stage.

\begin{tabular}{cccc}
\hline Stage & Descripion & eGFR $\mathrm{ml} / \mathrm{min} / 1.73 \mathrm{~m}^{2}$ & Cases \\
\hline 1 & Kidney damage with normal or $\uparrow$ eGFR & $\geq 90$ & 26 \\
2 & Kidney damage with mild $\downarrow$ eGFR & $60-89$ & 93 \\
3 & Moderate $\downarrow$ eGFR & $30-59$ & 45 \\
4 & Severe $\downarrow$ eGFR & $15-29$ & 5 \\
5 & Kidney failure $\downarrow$ eGFR & $<15$ (or dialysis) & 0 \\
\hline
\end{tabular}

There was no significant correlation of BAP with aging; however, TRACP5b did increase with age resulting in an equilateral correlation $(\mathrm{r}=0.226, p<0.01)$ (Figure 1). $\mathrm{P}$ increased, therefore $\mathrm{Ca}$ increased, resulting in an equilateral correlation $(\mathrm{r}=0.309, p<0.01)$. In addition, an increase in intact PTH negatively correlated with a decrease in $\mathrm{Ca}$ and $\mathrm{P}(\mathrm{r}=-0.403, p<0.01$ and $\mathrm{r}=-0.416, p<$ 0.01 , respectively) (Figure 2).

\section{Discussion}

$\mathrm{Ca}$ is supplied to the body via dietary intake and is absorbed in the small intestine. The quantity of reabsorption is coordinated with $\mathrm{Ca}$ excretion in the kidney. With aging, it is well accepted that there is a decline in both the Ca absorption in the intestinal tract and Ca reabsorption in the kidney [3] [4] [5]. We should draw our attention to the value of $\mathrm{Ca}$ and renal function in an elderly person with osteoporosis when regarding osteoporotic treatment. When the serum Ca levels decreases, it is sensed by a Ca perception receptor located on the surface of the chief cells in the parathyroid gland, and PTH secretion is promoted [6]. PTH decreases blood P levels by preventing $\mathrm{P}$ reabsorption in the proximal tubules of the kidney. It has been shown that when renal function drops, fibroblast growth factor 23 (FGF23) secretion is induced from early stage to prevent hyperphosphatemia [7]. FGF23 is a humoral factor produced by bone that controls calcitriol $(1.25(\mathrm{OH}) 2 \mathrm{D})$ production [8]. Serum Ca and P are main- 

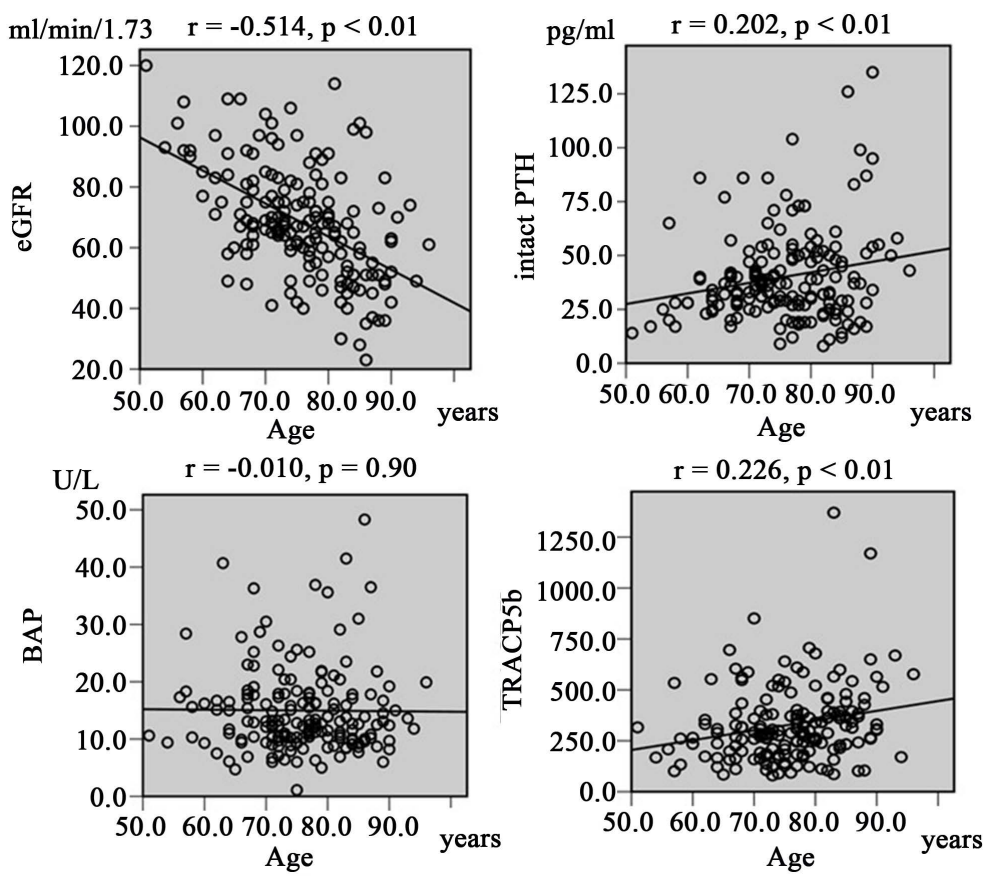

Figure 1. Correlation between age and different studied variables; The eGFR decreased with age resulting in a negative correlation $(\mathrm{r}=-0.514, p<0.01)$. Intact PTH increased with age resulting in an equilateral correlation $(\mathrm{r}=0.202, p<0.01)$. There was no significant correlation of BAP with ageing. TRACP $5 \mathrm{~b}$ did increase with age resulting in an equilateral correlation $(\mathrm{r}=0.226, p<0.01)$.
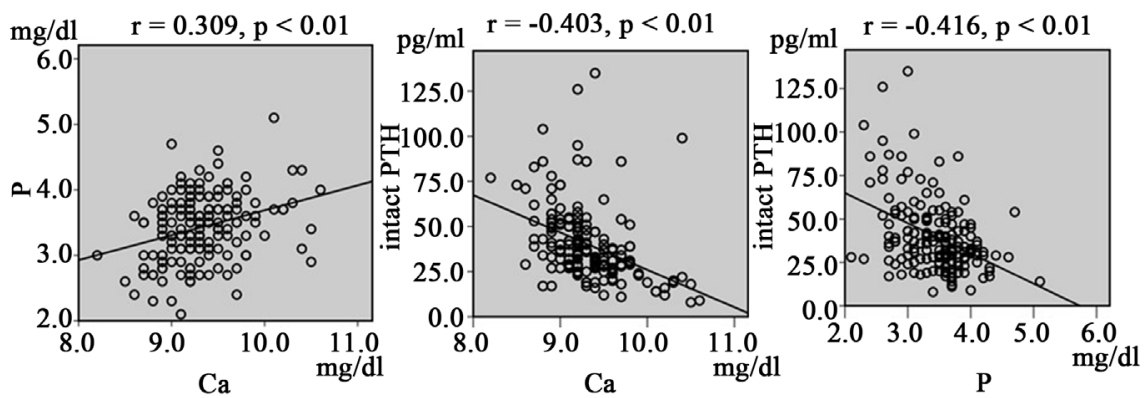

Figure 2. Correlation between $\mathrm{Ca}, \mathrm{P}$ and intact PTH; $\mathrm{P}$ increased, therefore $\mathrm{Ca}$ increased, resulting in an equilateral correlation $(\mathrm{r}=0.309, p<0.01)$. An increase in intact PTH negatively correlated with a decrease in $\mathrm{Ca}$ and $\mathrm{P}(\mathrm{r}=-0.403, p<0.01$ and $\mathrm{r}=-0.416, p<$ 0.01 , respectively).

tained at in an extremely narrow concentration range throughout such processes. However, when renal function begins to decline severely, the removal of $P$ to the urine via FGF23 and PTH is limited, and serum P rises [9] [10].

In our study, most cases presented with $\mathrm{Ca}, \mathrm{P}$, and $\mathrm{PTH}$ within the normal range, and patients did not present with any clinical manifestations. However, increased PTH did negatively correlate with low $\mathrm{Ca}$ and low P. McKane et al. [11] reported that failure of elderly women to increase their Ca intake to compensate for the age-related increases in Ca requirement contributes substantially to their development of increased parathyroid activity and increased bone resorption. Chronic increased PTH levels are catabolic for cortical bone [12]. 
Curtis et al. [13] reported that higher levels of PTH, even within the normal laboratory plasma reference range, were associated with considerably higher rates of hip BMD loss. This association was observed among patients with both normal and reduced renal function. On the other hand, Campos-Obando et al. [14] reported that serum $\mathrm{P}$ positively correlated with fracture risk independent of $\mathrm{BMD}$, and increased $\mathrm{P}$ levels, even within normal range, might be deleterious for bone health in the normal population. Therefore, even if $\mathrm{Ca}$ and $\mathrm{P}$ are within the normal range, in cases where the effect of the osteoporotic therapeutic drug is poor, it is necessary to consider measurement of intact PTH.

There are several limitations to this study. We were unable to consider the influence of each osteoporotic therapeutic drug on mineral bone metabolism [15] [16] [17]. In addition, we did not consider whether the level of intact PTH influences the difference in BMD. Thus, future long-term follow-up studies should be carried out to evaluate these problems.

\section{Conclusion}

In osteoporotic patients with no history of $\mathrm{CKD}$, an age-related decline in renal function was observed. Furthermore, a relationship was observed between the levels of intact PTH and $\mathrm{Ca}$ and $\mathrm{P}$. Even if $\mathrm{Ca}$ and $\mathrm{P}$ are in the normal range, in case of a poor effect of an osteoporotic therapeutic drug, it is necessary to consider the measurement of intact PTH.

\section{Competing Interests}

The authors declare that there is no conflict of interest regarding the publication of this paper.

\section{References}

[1] Nickolas, T.L., McMahon, D.J. and Shane, E. (2006) Relationship between Moderate to Severe Kidney Disease and Hip Fracture in the United States. Journal of the American Society of Nephrology, 17, 3223-3232. https://doi.org/10.1681/ASN.2005111194

[2] Kidney Disease (2009) Improving Global Outcomes (KDIGO) CKD-MBD Work Group. KDIGO Clinical Practice Guideline for the Diagnosis, Evaluation, Prevention, and Treatment of Chronic Kidney Disease-Mineral and Bone Disorder (CKDMBD). Kidney International, 76, S1-S130.

[3] Bullamore, J.R., Wilkinson, R., Gallagher, J.C., et al. (1970) Effect of Age on Calcium Absorption. The Lancet, 296, 535-537. https://doi.org/10.1016/S0140-6736(70)91344-9

[4] Heaney, R.P., Recker, R.R., Stegman, M.R., et al. (1989) Calcium Sbsorption in Women: Relationships to Calcium Intake, Estrogen Status, and Age. Journal of Bone and Mineral Research, 4, 469-475. https://doi.org/10.1002/jbmr.5650040404

[5] Eastell, R., Simmons, P.S., Colwell, A., et al. (1992) Nyctohemeral Changes in Bone Turnover Assessed by Serum Bone Gla-Protein Concentration and Urinary Deoxypyridinoline Excretion: Effects of Growth and Aging. Clinical Science, 83, 375-382. https://doi.org/10.1042/cs0830375

[6] Conigrave, A.D. (2016) The Calcium-Sensing Receptor and the Parathyroid: Past, 
Present, Future. Frontiers in physiology, 7, 1-13. https://doi.org/10.3389/fphys.2016.00563

[7] Shigematsu, T., Kazama, J.J., Yamashita, T., et al. (2004) Possible Involvement of Circulating Fibroblast Growth Factor 23 in the Development of Secondary Hyperparathyroidism Associated with Renal Insufficiency. American Journal of Kidney Disease, 44, 250-256. https://doi.org/10.1053/j.ajkd.2004.04.029

[8] Shimada, T., Hasegawa, H., Yamazaki, Y., et al. (2004) FGF-23 Is a Potent Regulator of Vitamin D Metabolism and Phosphate Homeostasis. Journal of Bone and Mineral Research, 19, 429-435. https://doi.org/10.1359/JBMR.0301264

[9] Levin, A., Bakris, G.L., Molitch, M., et al. (2007) Prevalence of Abnormal Serum Vitamin D, PTH, Calcium, and Phosphorus in Patients with Chronic Kidney Disease; Result of Study to Evaluate Early Kidney Disease. Kidney International, 71, 31-38. https://doi.org/10.1038/sj.ki.5002009

[10] Komaba, H. and Fukunaga, M. (2010) FGF23-Parathyroid Interaction; Implications in Chronic Kidney Disease. Kidney International, 77, 292-298.

https://doi.org/10.1038/ki.2009.466

[11] McKane, W.R., Khosla, S., Egan, K.S., et al. (1996) Role of Calcium Intake in Modulating Age-Related Increase in Parathyroid Function and Bone Resorption. Journal of Clinical Endocrinology and Metabolism, 81, 1699-1703.

[12] Nickolas, T.L., Stein, E.M., Dworakowski, E., et al. (2013) Rapid Cortical Bone Loss in Patients with Chronic Kidney Disease. Journal of Bone and Mineral Research, 28, 1811-1820. https://doi.org/10.1002/jbmr.1916

[13] Curtis, J.R., Ewing, S.K., Bauer, D.C., et al. (2012) Association of Intact Parathyroid Hormone Levels with Subsequent Hip BMD Loss: The Osteoporotic Fractures in Men (MrOS) Study. The Journal Clinical of Endocrinology and Metabolism, 97, 1937-1944. https://doi.org/10.1210/jc.2011-2431

[14] Campos-Obando, N., Koek, W.N., Hooker, E.R., et al. (2017) Serum Phosphate Is Associated with Fracture Risk: The Rotterdam Study and MrOS. Journal of Bone and Mineral Research, 32, 1182-1193. https://doi.org/10.1002/jbmr.3094

[15] Matsumoto, T., Miki, T., Hagino, H., et al. (2005) A New Active Vitamin D, ED-71, Increases Bone Mass in Osteoporotic Patients under Vitamin D Supplementation: A Randomized, Double-Blind. Placebo-Controlled Clinical Trial. The Journal Clinical of Endocrinology and Metabolism, 90, 5031-5036. https://doi.org/10.1210/jc.2004-2552

[16] Orimo, H., Shiraki, M., Tomita, A., et al. (1998) Effects of Menatetrenone on the Bone and Calcium Metabolism in Osteoporosis: A Double-Blind Placebo-Controlled Study. Journal of Bone and Mineral Metabolism, 16, 106-112. https://doi.org/10.1007/s007740050034

[17] Papapetrou, P.D. (2009) Bisphosphonate-Associated Adverse Events. Hormones, 8, 96-110. https://doi.org/10.14310/horm.2002.1226 
Submit or recommend next manuscript to SCIRP and we will provide best service for you:

Accepting pre-submission inquiries through Email, Facebook, LinkedIn, Twitter, etc. A wide selection of journals (inclusive of 9 subjects, more than 200 journals)

Providing 24-hour high-quality service

User-friendly online submission system

Fair and swift peer-review system

Efficient typesetting and proofreading procedure

Display of the result of downloads and visits, as well as the number of cited articles Maximum dissemination of your research work

Submit your manuscript at: http://papersubmission.scirp.org/

Or contact aar@scirp.org 